\title{
Expression and clinical significance of mammalian target of rapamycin/P70 ribosomal protein S6 kinase signaling pathway in human colorectal carcinoma tissue
}

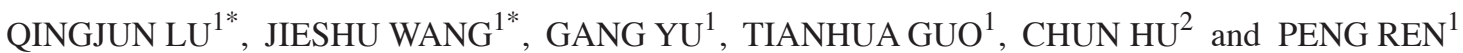 \\ ${ }^{1}$ Department of General Surgery, Binzhou Central Hospital, Binzhou Medical College, Binzhou, Shandong; \\ ${ }^{2}$ Department of Oncology, Ruijin Hospital, Shanghai Jiaotong University, Shanghai, P.R. China
}

Received May 17, 2014; Accepted February 11, 2015

DOI: $10.3892 / 01.2015 .3228$

\begin{abstract}
The activation of mammalian target of rapamycin (mTOR) has been reported in tumor development, but the role of mTOR in colorectal carcinomas remains unclear. The aim of the present study was to investigate the significance of mTOR and its downstream effector $70 \mathrm{kDa}$ ribosomal protein S6 kinase (P70S6K) in human colorectal carcinomas. The phosphorylated (p-)mTOR and p-P70S6K proteins were examined by immunohistochemistry performed on tissue microarray containing tissue samples obtained from colorectal carcinoma $(n=111)$, adenomatous polyps $(n=40)$ and normal colonic mucosa $(n=40)$, with a comparison between the expression of these proteins and the clinicopathological parameters of patients with carcinomas. The positive expression rates of p-mTOR and p-P70S6k were 60.4 and $65.8 \%$, respectively, in colorectal carcinoma tissue, which was significantly increased compared with the tissue from adenomatous polyps (27.5 and 20\%, respectively) and normal colonic mucosa $(10.0$ and $5.0 \%$, respectively) $(\mathrm{P}<0.05)$. Overexpression of the $\mathrm{p}-\mathrm{mTOR}$ and $\mathrm{p}-\mathrm{P} 70 \mathrm{~S} 6 \mathrm{~K}$ proteins was significantly associated with the tumor-node-metastasis stage, the occurrence of distal and lymph node metastasis and the degree of differentiation. Aberrant expression of p-mTOR and p-P70S6K may contribute to the pathogenesis, growth, invasion and metastasis of colorectal carcinoma. The phosphorylation of these proteins was considered to be a promising marker to indicate the aggressive behaviors and prognosis of colorectal carcinomas. The overexpression of
\end{abstract}

Correspondence to: Mr. Peng Ren, Department of General Surgery, Binzhou Central Hospital, Binzhou Medical College, 108 Huanchengnan Road, Binzhou, Shandong 256600, P.R. China E-mail: luqjmed@163.com

*Contributed equally

Key words: colorectal cancer, mammalian target of rapamycin/70 $\mathrm{kDa}$ ribosomal protein S6 kinase, reverse transcription-polymerase chain reaction, immunohistochemistry the mTOR/P70S6K signaling pathway may play an important role in colorectal carcinoma carcinogenesis. The expression of p-mTOR and p-P70S6K was considered as a promising marker to indicate the aggressive behaviors and prognosis of human colorectal carcinomas.

\section{Introduction}

Cancer is the leading cause of mortality in economically developed countries and is the second leading cause of mortality in developing countries. The burden of cancer is increasing in economically developing countries as a result of population aging and growth, in addition to an increasing adoption of cancer-associated lifestyle choices, including smoking, physical inactivity and a Western diet (1). Based on the GLOBOCAN 2008 estimates (2), 12.7 million cancer cases and 7.6 million cancer-associated mortalities are estimated to have occurred in that year. Of these, $56 \%$ of the cases and $64 \%$ of the mortalities occurred in the economically developing world (2). Colorectal cancer is the third most commonly diagnosed cancer in males and the second most commonly diagnosed cancer in females, with $>1.2$ million novel cancer cases and 608,700 mortalities estimated to occur each year. Despite considerable advances in modern therapeutic strategies, the overall survival time of patients undergoing complete resection of carcinomas is short (3). Therefore, clarification of the molecular mechanisms of colorectal carcinoma and the identification of a good biomarker to indicate the carcinogenesis and subsequent progression of the carcinoma is of considerable significance for the prevention, treatment and evaluation of prognosis of this disease. A potential candidate biomarker for colorectal carcinoma is mammalian target of rapamycin (mTOR), a serine/threonine protein kinase that plays a key role in regulating important cellular functions, including cell proliferation, growth, survival and mobility, and angiogenesis (4-11). In several non-colorectal tumors, the activation of the mTOR pathway and overexpression of the mTOR protein are associated with an increasingly aggressive clinical course, and have been reported to be useful for targeted therapy (12-14). In the present study, the role of the mTOR/70 kDa ribosomal protein S6 kinase (P70S6K) signaling pathway in the stepwise development of colorectal 
Table I. Expression of p-mTOR in adenocarcinomas, adenomatous polyps and normal mucosa.

\begin{tabular}{lcccr}
\hline & & \multicolumn{2}{c}{ Expression of p-mTOR $^{\mathrm{a}}$} & \\
\cline { 3 - 4 } Tissue type & Total, $\mathrm{n}$ & Yes, $\mathrm{n}(\%)$ & No, $\mathrm{n}(\%)$ & $\chi^{2}$ \\
\hline Adenocarcinoma & 111 & $67(60.4)$ & $29(39.6)$ & \\
Adenomatous polyps & 40 & $11(27.5)$ & $36(90.0)$ & 85.8 \\
Normal mucosa & 40 & $4(10.0)$ & & \\
\hline
\end{tabular}

${ }^{\mathrm{a}} \mathrm{P}<0.001$ compared to normal mucosa and adenomatous polps.

carcinoma was investigated. The association between the expression of mTOR and P70S6K and the clinical pathological factors of the carcinoma was also investigated in the present study, as well as the importance of the role of this pathway in colorectal carcinoma.

\section{Materials and methods}

A total of 111 patients with colorectal carcinoma that underwent curative surgery without prior treatment at the Binzhou Central Hospital (Binzhou, China) between June 2005 and July 2013 were enrolled in the present study. These patients consisted of 58 men and 53 women with ages ranging between 30 and 69 years. The carcinoma lesions were located in the colon in 79 patients and rectum in 32 patients. Of these patients, histological grading resulted in 24 being classified as stage I, 28 being classified as II, 45 being classified as stage III and 14 being classified as stage IV, according to the tumor-node-metastasis (TNM) staging system revised by the Union for International Cancer Control (15). In addition, 40 samples from adenomatous polyps and 40 samples from normal colonic mucosa were also obtained from the Binzhou Central Hospital. None of the patients underwent chemotherapy or radiotherapy prior to surgery and all patients provided consent for the use of tumor tissue for clinical research. This study was approved by the Ethics Committee of Binzhou Medical College (Binzhou, China).

Immunohistochemistry. The resected specimens were fixed in $10 \%$ formalin, cut into $4-\mathrm{mm}$ thick slices and mounted onto adhesive-coated slides. The slides were deparaffinized in xylene twice for $10 \mathrm{~min}$ and rehydrated through descending concentrations of ethanol. Antigen retrieval was performed in $0.01 \mathrm{~mol} / 1$ citrate buffer $(\mathrm{pH} \mathrm{6.0)}$ ) for $2 \mathrm{~min}$ and $30 \mathrm{sec}$ at $100^{\circ} \mathrm{C}$, using a microwave oven. Endogenous peroxidase activity was blocked with $0.3 \%$ hydrogen peroxidase for $10 \mathrm{~min}$. Subsequent to washing with phosphate-buffered saline (PBS), the sections were incubated with blocking serum for $1 \mathrm{~h}$. The $\mathrm{p}-\mathrm{mTOR}$ and $\mathrm{p}-\mathrm{P} 70 \mathrm{~S} 6 \mathrm{~K}$ proteins were detected using primary polyclonal rabbit antibodies against p-mTOR and p-P70S6K, respectively. Specimens were incubated with the primary antibody overnight at $4^{\circ} \mathrm{C}$. Using an Olympus microscope (Olympus, Tokyo, Japan), the protein expression was evaluated by three pathologists that were blinded to the clinical data of the patients, and the values were then averaged.
Score evaluation. The intensity of staining was scored as follows: 0 , no expression, no brown staining; 1 , weak expression, light brown staining; 2, moderate expression, intermediate brown staining; and 3 , strong expression, dark brown staining. The extent of staining was scored based on the proportion of cells stained in the respective lesions, as follows: $0,<5 \%$ of cells; $1,5-25 \%$ of cells; $2,26-50 \%$ of cells; 3 , $51-75 \%$; and $4,>75 \%$ of cells. The final score was determined by multiplying the intensity of staining score by the extent of staining score, yielding a range between 0 and 12. Tissues that scored between 9 and 12 were defined as exhibiting a preserved or strong staining pattern (++), 5-8 was defined as a weak staining pattern (+) and 0-4 was defined as markedly reduced or no expression (-). In particular, under-expression was defined as no staining, or positive staining in the tumor tissue that was decreased compared with the matched normal tissue. Normal expression was defined as positive staining that was similar to the matched normal tissue, and over-expression was defined as positive staining that was increased compared with the matched normal tissue.

Reverse transcription-polymerase chain reaction (RT-PCR). The one-step RT-PCR system (Thermo Fisher Scientific, Pittsburgh, PA, USA) was used to isolate the RNA from tissues. The primer sequences used were as follows: mTOR sense, 5'-CTGGGACTCAAATGTGTGCAGTTC-3' and antisense, 5'-GAACAATAGGGTGAATGATCCGGG-3'; and P70S6K sense, 5'-TACTTCGGGTACTTGGTAA-3' and antisense, 5'-GATGAAGGGATGGTTTACT-3'. A 302-bp $\beta$-actin fragment was amplified as an internal control. The primers used for $\beta$-actin were as follows: forward, 5'-TCCTCCCTGGAGAAGAGCTA-3' and reverse, 5'-TCA GGAGGAGCAATGATGTTG-3'. Subsequent to denaturation by heating at $95^{\circ} \mathrm{C}$ for $1 \mathrm{~min}$ the samples were exposed to 30 cycles ( $\beta$-actin, 25 cycles) at $95^{\circ} \mathrm{C}$ for $30 \mathrm{sec}, 60^{\circ} \mathrm{C}$ for $30 \mathrm{sec}$ and $68^{\circ} \mathrm{C}$ for $90 \mathrm{sec}$, with a final extension at $68^{\circ} \mathrm{C}$ for $10 \mathrm{~min}$.

Western blot analysis. Whole-cell lysates were prepared from human colorectal cancer or normal colorectal tissue specimens. Standard western blotting was performed using primary polyclonal rabbit anti-mouse p-mTOR (1:1,000; cat. no. 5536S; Cell Signaling Technology, Inc., Danvers, MA, USA) and p-P70S6K (1:1,000; cat. no. 9234S; Cell Signaling Technology, Inc.) antibodies. Polyclonal rabbit anti-human $\beta$-actin antibody (1:1,000; cat. no. sc-130656; Santa Cruz Biotechnology, Inc., Dallas, TX, USA) was used 
Table II. Expression of p-P70S6K in adenocarcinomas, adenomatous polyps and normal mucosa.

\begin{tabular}{lcccc}
\hline & & \multicolumn{2}{c}{ Expression of $\mathrm{p}-\mathrm{P} 70 \mathrm{~S} 6 \mathrm{~K}^{\mathrm{a}}$} & \\
\cline { 3 - 4 } Tissue type & Total, $\mathrm{n}$ & Yes, $\mathrm{n}(\%)$ & No, $\mathrm{n}(\%)$ & $38(34.2)$ \\
\hline Adenocarcinoma & 111 & $73(65.8)$ & $32(80.0)$ & $\chi^{2}$ \\
Adenomatous polyps & 40 & $8(20.0)$ & $38(95.0)$ & 102.4 \\
Normal mucosa & 40 & $2(5.0)$ & & \\
\hline
\end{tabular}

${ }^{\text {a }}<0.001$ compared to normal mucosa and adenomatous polps. p-P70S6K, phosphorylated P70 ribosomal protein S6 kinase.

Table III. Differences in the overexpression of p-mTOR and p-70S6k in association with clinicopathology parameters of colorectal cancers patients.

\begin{tabular}{|c|c|c|c|c|c|}
\hline \multirow{2}{*}{$\begin{array}{l}\text { Clinicopathological } \\
\text { features }\end{array}$} & \multirow[b]{2}{*}{ Total, $\mathrm{n}$} & \multicolumn{2}{|c|}{ p-mTOR overexpression } & \multicolumn{2}{|c|}{ p-P70S6K overexpression } \\
\hline & & $\mathrm{n}$ & P-value & $\mathrm{n}$ & P-value \\
\hline \multicolumn{6}{|l|}{ Gender } \\
\hline Male & 58 & 40 & & 39 & \\
\hline Female & 53 & 29 & 0.098 & 29 & 0.211 \\
\hline \multicolumn{6}{|l|}{ Age, years } \\
\hline$<60$ & 42 & 24 & & 26 & \\
\hline$\geq 60$ & 69 & 43 & 0.404 & 42 & 0.979 \\
\hline \multicolumn{6}{|l|}{ Location } \\
\hline Colon & 79 & 47 & & 48 & \\
\hline Rectum & 32 & 21 & 0.459 & 20 & 0.771 \\
\hline \multicolumn{6}{|l|}{ TNM stage } \\
\hline $\mathrm{I} / \mathrm{II}$ & 52 & 26 & & 21 & \\
\hline III/IV & 59 & 43 & $<0.001$ & 47 & $<0.001$ \\
\hline \multicolumn{6}{|l|}{$\begin{array}{l}\text { Lymph node } \\
\text { metastasis }\end{array}$} \\
\hline No & 59 & 19 & & 26 & \\
\hline Yes & 52 & 36 & 0.021 & 40 & $<0.001$ \\
\hline \multicolumn{6}{|l|}{ Distant metastasis } \\
\hline No & 99 & 56 & & 49 & \\
\hline Yes & 12 & 10 & 0.029 & 11 & 0.034 \\
\hline \multicolumn{6}{|l|}{ Differentiation } \\
\hline Well & 11 & 4 & & 5 & \\
\hline Moderate & 58 & 27 & & 25 & \\
\hline Poor & 42 & 35 & 0.006 & 36 & 0.002 \\
\hline
\end{tabular}

p-mTOR, phosphorylated mammalian target of rapamycin; p-P70S6K, phosphorylated $70 \mathrm{kDa}$ ribosomal protein S6 kinase; TNM, tumor-node-metastasis.

as the loading control. Horseradish peroxidase-conjugated goat anti-rabbit IgG (1:2,000; cat. no. sc-2004; Santa Cruz Biotechnology, Inc.) was used as the secondary antibody.

Statistical analysis. SPSS software, version 17.0, (SPSS, Inc., Chicago, IL, USA) was employed to analyze all data. Differences between groups were compared using the $\chi^{2}$ test or Pearson's product-moment correlation. $\mathrm{P}<0.05$ was considered to indicate a statistically significant difference.

\section{Results}

Association between p-mTOR and p-P70S6K expression and colorectal carcinoma. As shown in Table I, four out of 40 normal colonic mucosa tissues $(10.0 \%)$ demonstrated weak p-mTOR expression. By contrast, p-mTOR was weakly to moderately expressed in 11 out of 40 tissues samples from adenomatous polyps (27.5\%) and over-expressed in 67 out of 111 colorectal adenocarcinoma tissue samples (60.4\%) 


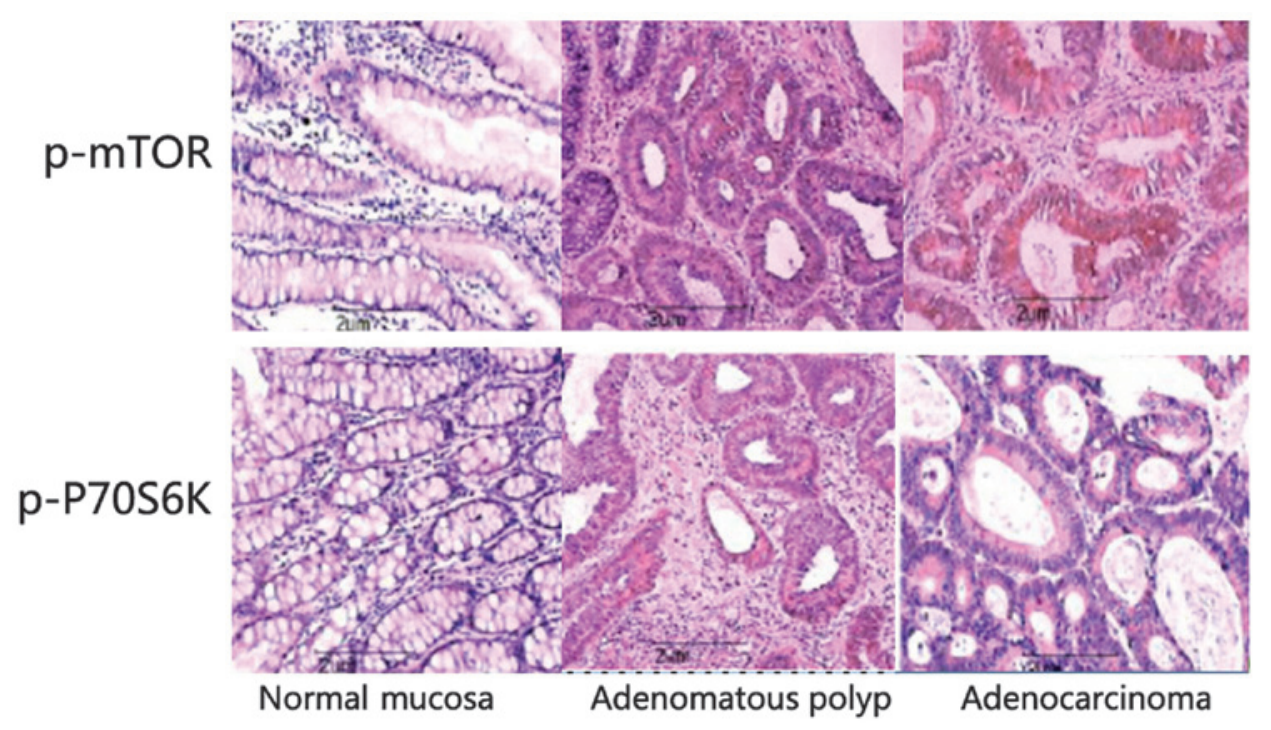

Figure 1. Immunohistochemical staining in normal colonic mucosa, adenomatous polyps and colorectal adenocarcinoma tissue samples. Strong staining for p-mTOR was observed in the cytoplasm, while p-P70S6K was strongly expressed in the cytoplasm and nucleus. p-mTOR expression was observed in normal colonic mucosa, adenomatous polyps and colorectal adenocarcinomas, whereas the p-P70S6K protein was immunoreactive in non-neoplastic mucosa, adenoma and carcinoma. p-mTOR, phosphorylated mammalian target of rapamycin; p-P70S6K, posphorylated 70 kDa ribosomal protein S6 kinase.

A

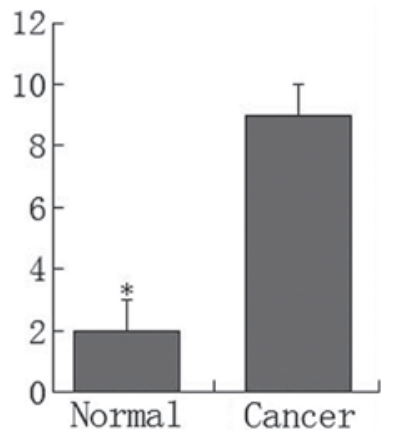

B

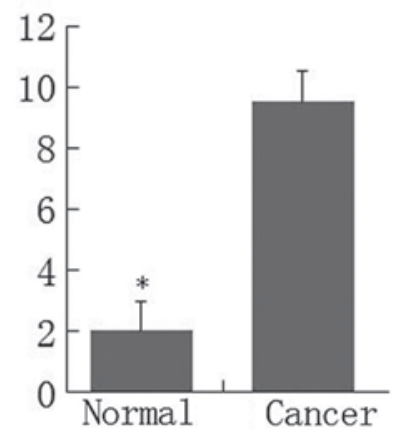

Figure 2. Immunohistochemistry scores for the expression of the (A) phosphorylated mammalian target of rapamycin and (B) phosphorylated $70 \mathrm{kDa}$ ribosomal protein S6 kinase proteins in human colorectal cancer and matched normal colorectal tissues. ${ }^{*} \mathrm{P}<0.05$ compared to cancer tissue.

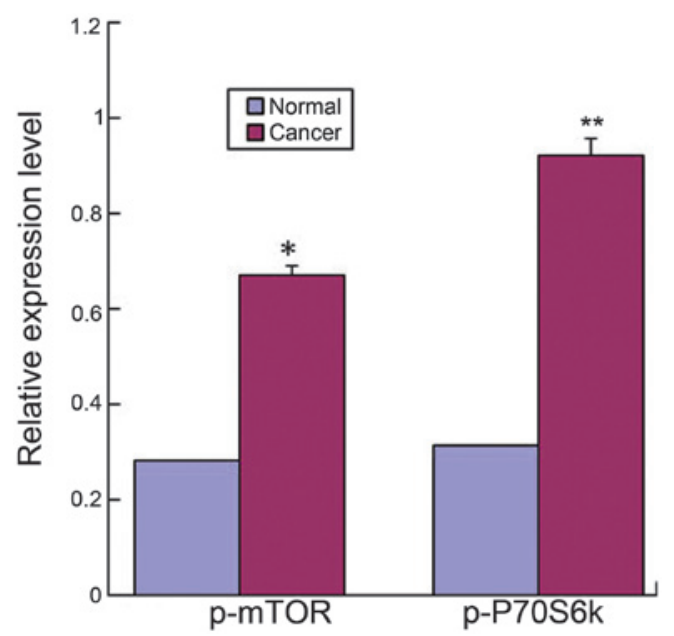

Figure 3. Reverse transcription-polymerase chain reaction analysis of p-P70S6K and p-mTOR from colorectal cancer and normal colorectal tissue specimens. ${ }^{*} \mathrm{P}<0.05$ and ${ }^{* *} \mathrm{P}<0.01$ compared to control tissue.p-P70S6K, phosphorylated $70 \mathrm{kDa}$ ribosomal protein S6 kinase; p-mTOR, phosphorylated mammalian target of rapamycin.

$(\mathrm{P}<0.001)$. In normal colonic mucosa samples, only two out of 40 tissue samples (5.0\%) demonstrated weak p-P70S6K expression. By contrast, p-P70S6K was weakly to moderately expressed in eight out of 40 adenomatous polyp tissue samples (20.0\%) and over-expressed in 73 out of 111 colorectal adenocarcinoma tissues (65.8\%) (Table II). Increased expression of p-mTOR and p-P70S6K was observed in the membrane and cytoplasm of tumor cells. The $\chi^{2}$ test indicated that the expression of p-mTOR and p-P70S6K was significantly associated with colorectal adenocarcinoma tissues $(\mathrm{P}<0.001$; Tables I and II; Fig. 1).

Additional analysis indicated that the p-mTOR and $\mathrm{p}-\mathrm{P} 70 \mathrm{~S} 6 \mathrm{~K}$ proteins were overexpressed in the primary tumor tissue compared with the normal colorectal tissue. The scores for $\mathrm{p}-\mathrm{mTOR}$ and $\mathrm{p}-\mathrm{P} 70 \mathrm{~S} 6 \mathrm{~K}$ expression in adenocarcinomas were significantly higher compared with the normal mucosa $(\mathrm{P}<0.05)$ (Fig. 2). The results from RT-PCR also indicated that the mRNAs for p-mTOR and p-P70S6K in colorectal adenocarcinomas were significantly higher compared with the normal tissues (Fig. 3). In addition, western blot analysis indicated that the expression of the p-mTOR and p-P70S6K proteins was significantly higher in adenocarcinoma tissues compared with normal tissues (Fig. 4).

Association between the expression of p-mTOR and p-P70S6K and clinicopathological characteristics of colorectal adenocarcinoma. By evaluating the clinical significance of p-mTOR and p-P70S6K overexpression, it was found that overexpression of the p-mTOR protein was significantly associated with the TNM stage $(\mathrm{P}<0.001)$, occurrence of lymph node metastasis $(\mathrm{P}=0.021)$, occurrence of distant metastasis $(\mathrm{P}=0.029)$ and degree of differentiation $(\mathrm{P}=0.006)$ in colorectal adenocarcinoma tissues. In addition, p-P70S6K overexpression was also associated with the TNM stage $(\mathrm{P}<0.001)$, incidence of lymph node metastasis $(\mathrm{P}<0.001)$, occurrence of distant metastasis $(\mathrm{P}=0.034)$ and degree of differentiation $(\mathrm{P}=0.002)$ in colorectal adenocarcinoma (Table III). 


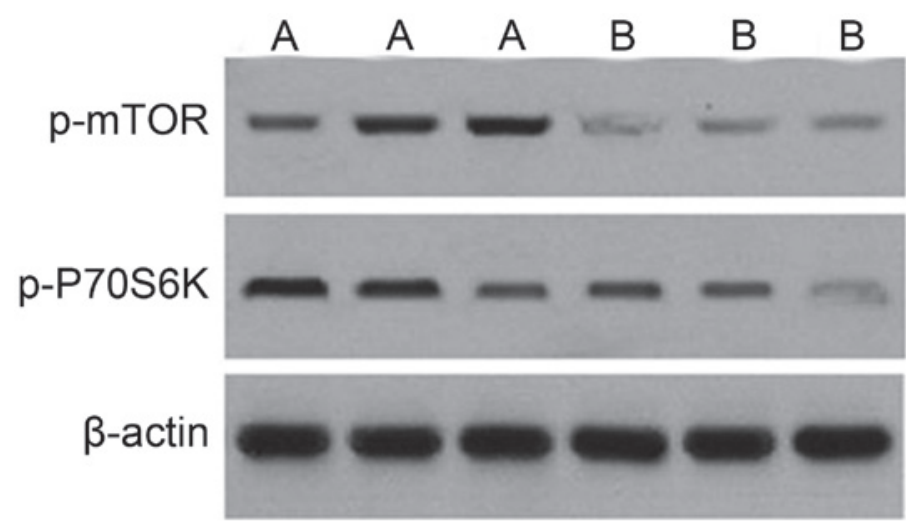

Figure 4. Western blot analysis of the expression of p-mTOR and p-P70S6K from three paired (A) colorectal cancer and (B) normal colorectal tissue specimens. p-mTOR, phosphorylated mammalian target of rapamycin; p-P70S6K, phosphorylated $70 \mathrm{kDa}$ ribosomal protein $\mathrm{S} 6$ kinase.

\section{Discussion}

mTOR is a serine/threonine kinase that is involved in multiple intracellular signaling pathways, promoting tumor growth. In the presence of sufficient nutrients, mTOR is phosphorylated through the phosphoinositide 3-kinase (PI3K)/Akt signaling pathway, resulting in the transmittance of a positive signal to P70S6K, and therefore participates in the inactivation of the eukaryotic translation initiation factor $4 \mathrm{E}$ inhibitor. The $\mathrm{PI} 3 \mathrm{~K} / \mathrm{Akt} / \mathrm{mTOR}$ signaling pathway, in particular, is frequently altered in non-colorectal cancers, including gastric cancer (16), biliary tract adenocarcinoma (17), pancreatic ductal adenocarcinoma (18), lung carcinoma (19), urinary bladder carcinoma (20), prostate cancer (21), cervical carcinoma (22), breast cancer (23) and renal cell carcinoma (24). Activated p-mTOR has been demonstrated to be associated with tumors in numerous cancer tissues. It has been found that the expression of the p-mTOR protein is elevated in extrahepatic cholangiocarcinoma (25) and the expression of the p-P70S6K protein is increased in high-grade squamous intraepithelial lesions and cervical squamous cell carcinoma compared with the normal cervical epithelium (22). In the present study, the rate of the positive expression of p-P70S6K and p-mTOR was detected to be significantly higher in colorectal cancer tissues compared with normal tissues. Furthermore, the p-P70S6K and p-mTOR expression levels were found to be higher in colorectal adenocarcinoma tissue samples compared with normal colonic mucosa, which indicates that activated mTOR is highly associated with colorectal cancer and plays a key role in tumor carcinogenesis.

It has been suggested that the expression of p-P70S6K and p-mTOR is associated with various clinicopathological variables in certain non-colorectal tumors. For example, Yu et al reported that overexpression of the mTOR protein was significantly associated with tumor differentiation, $\mathrm{T} 1$ and 2 tumors and stage I-III disease, whereas p-mTOR overexpression was significantly associated with the occurrence of lymph node metastasis and all stages of disease (26). Wang et al reported that the expression of mTOR and p-mTOR may play an important role in colorectal carcinogenesis, with an association between the expression of mTOR and the degree of differentiation, invasiveness and metastatic ability of the lesions (27). No et al found that the expression of mTOR was highly associated with old age and menopausal status, but not with other clinicopathological characteristics (28). Dobashi et al identified that the p-mTOR expression in lung adenocarcinoma specimens was associated with the grade of histological differentiation, whereas the expression of p-mTOR was associated with lymph node metastasis in squamous cell carcinoma specimens (19). Although Herberger et al (17)found that p-mTOR was expressed in 56 out of 88 biliary tract carcinoma samples, no association was identified between the expression and any clinicopathological variables. However, the expression did predict the survival time of the patients (17).

Activation of P70S6K is achieved through the phosphorylation of multiple serine/threonine residues by stimulation with growth factors, including epidermal growth factor, thrombin and lysophosphatidic acid (29,30). Li et al reported that the expression of p-P70S6K was found to be inversely associated with the tumor size, depth of invasion, lymph node metastasis and Union for International Cancer Control staging when the aggressive behaviors of carcinoma were compared with nuclear p-P70S6K expression (31). Zhang et al (32) identified that the expression level of $\mathrm{p}$-mTOR and p-ribosomal protein S6 kinase $\beta 1$ (RPS6KB1) was significantly higher in NSCLC tumor specimens compared with adjacent non-cancerous normal lung tissues. In this study, a high expression level of p-mTOR or p-RPS6KB1 in NSCLC was associated with a shorter overall survival time, and multivariate analysis indicated that a high level of p-mTOR expression was an independent prognostic factor in patients with NSCLC (32). In the present study, it was found that overexpression of the p-P70S6K and p-mTOR proteins was significantly associated with the degree of differentiation, occurrence of distant metastasis, TNM stage and occurrence of lymph node metastasis. These findings suggest that the mTOR signal pathway performs an important role in colorectal tumorigenesis. To the best of our knowledge, the present study is the first to investigate the association between p-mTOR and p-P70S6K overexpression in colorectal cancer tissues and the clinicopathological characteristics of colorectal cancer patients. The present results also indicated that the mTOR signaling pathway was frequently activated and that overexpression of mTOR may be an important step in the carcinogenesis and progression of human colorectal cancer.

At present, it is hypothesized that targeting mTOR with small interfering (si)RNA may inhibit the proliferation of 
cancer cell proliferation. Ji et al reported that targeting the expression of p-mTOR with specific siRNA reduced the growth and overall survival rate of Hela cervical cancer cells in vitro (33). The present study also indicates that downregulating the mTOR signaling pathway may be a promising novel molecular target for designing novel therapeutic strategies to control colorectal cancer. This hypothesis is supported by a previous study that reported targeting mTOR complex 2 inhibits colon cancer cell proliferation in vitro and tumor formation in vivo (34). In summary, the present study indicated that $\mathrm{p}-\mathrm{P} 70 \mathrm{~S} 6 \mathrm{~K}$ and $\mathrm{p}-\mathrm{mTOR}$ are overexpressed in human colorectal carcinoma, and also indicated that the overexpression of p-P70S6K and p-mTOR is associated with certain clinical characteristics. This suggests that p-P70S6K and p-mTOR may play a important role in colorectal cancer and may be employed to indicate the biological behaviors of colorectal carcinoma in clinicopathological practice.

\section{Acknowledgements}

The present study was supported by a grant from the National Science and Technology Special Foundation for Major Infectious Diseases Prevention and Control (grant no. 2008Ex 10002019).

\section{References}

1. World Health Organization: The Global Burden of Disease: 2004 Update. World Health Organization, Geneva, 2008.

2. Ferlay J, Shin HR, Bray F, et al: Estimates of worldwide burden of cancer in 2008: GLOBOCAN 2008. Int J Cancer 127: 2893-2917, 2010.

3. Otake S, Takeda H, Fujishima S, et al: Decreased levels of plasma adiponectin associated with increased risk of colorectal cancer. World J Gastroenterol 16: 1252-1257, 2010.

4. Buck E, Eyzaguirre A, Brown E, et al: Rapamycin synergizes with the epidermal growth factor receptor inhibitor erlotinib in non-small-cell lung, pancreatic, colon, and breast tumors. Mol Cancer Ther 5: 2676-2684, 2006.

5. Pene F, Claessens YE, Muller O, et al: Role of the phosphatidylinositol 3-kinase/Akt and mTOR/P70S6-kinase pathways in the proliferation and apoptosis in multiple myeloma. Oncogene 21: 6587-6597, 2002.

6. Shaw RJ and Cantley LC: Ras, PI(3)K and mTOR signalling controls tumour cell growth. Nature 441: 424-430, 2006.

7. Foster DA: Phosphatidic acid signaling to mTOR: Signals for the survival of human cancer cells. Biochim Biophys Acta 1791: 949-955, 2009.

8. Jiang BH and Liu LZ: Role of mTOR in anticancer drug resistance: Perspectives for improved drug treatment. Drug Resist Updat 11: 63-76, 2008

9. Wang $X$ and Proud CG: The mTOR pathway in the control of protein synthesis. Physiology (Bethesda) 21: 362-369, 2006

10. Kim EK, Kim HA, Koh JS, et al: Phosphorylated S6K1 is a possible marker for endocrine therapy resistance in hormone receptor-positive breast cancer. Breast Cancer Res Treat 126 : 93-99, 2011.

11. Han D, Li SJ, Zhu YT, et al: LKB1/AMPK/mTOR signaling pathway in non-small-cell lung cancer. Asian Pac J Cancer Prev 14: 4033-4039, 2013.

12. Raymond E, Alexandre J, Faivre S, et al: Safety and pharmacokinetics of escalated doses of weekly intravenous infusion of CCI-779, a novel mTOR inhibitor, in patients with cancer. J Clin Oncol 22: 2336-2347, 2004.

13. O'Donnell A, Faivre S, Burris HA III, et al: Phase I pharmacokinetic and pharmacodynamic study of the oral mammalian target of rapamycin inhibitor everolimus in patients with advanced solid tumors. J Clin Oncol 26: 1588-1595, 2008.

14. Rizell M, Andersson M, Cahlin C, et al: Effects of the mTOR inhibitor sirolimus in patients with hepatocellular and cholangiocellular cancer. Int J Clin Oncol 13: 66-70, 2008.
15. Benson AB III, Bekaii-Saab T, Chan E, et al; National Comprehensive Cancer Network: Localized colon cancer, version 3.2013: featured updates to the NCCN Guidelines. J Natl Compr Canc Netw 11: 519-528, 2013.

16. Murayama T, Inokuchi M, Takagi Y, Yamada H, Kojima K, Kumagai J, Kawano T and Sugihara K: Relation between outcomes and localisation of p-mTOR expression in gastric cancer. Br J Cancer 100: 782-788, 2009.

17. Herberger B, Puhalla H, Lehnert M, Wrba F, Novak S, Brandstetter A, Gruenberger B, Gruenberger T, Pirker R and Filipits M: Activated mammalian target of rapamycin is an adverse prognostic factor in patients with biliary tract adenocarcinoma. Clin Cancer Res 13: 4795-4799, 2007.

18. Pham NA, Schwock J, Iakovlev V, Pond G, Hedley DW and Tsao MS: Immunohistochemical analysis of changes in signaling pathway activation downstream of growth factor receptors in pancreatic duct cell carcinogenesis. BMC Cancer 8: 43, 2008.

19. Dobashi Y, Suzuki S, Matsubara H, Kimura M, Endo S and Ooi A: Critical and diverse involvement of $\mathrm{Akt} / \mathrm{mammalian}$ target of rapamycin signaling in human lung carcinomas. Cancer 115: 107-118, 2009.

20. Sun CH, Chang $\mathrm{YH}$ and Pan CC: Activation of the $\mathrm{PI} 3 \mathrm{~K} / \mathrm{Akt} / \mathrm{mTOR}$ pathway correlates with tumour progression and reduced survival in patients with urothelial carcinoma of the urinary bladder. Histopathology 58: 1054-1063, 2011.

21. Kremer CL, Klein RR, Mendelson J, Browne W, Samadzedeh LK, Vanpatten K, Highstrom L, Pestano GA and Nagle RB: Expression of mTOR signaling pathway markers in prostate cancer progression. Prostate 66: 1203-1212, 2006.

22. Feng W, Duan X, Liu J, Xiao J and Brown RE: Morphoproteomic evidence of constitutively activated and overexpressed mTOR pathway in cervical squamous carcinoma and high grade squamous intraepithelial lesions. Int J Clin Exp Pathol 2: 249-260, 2009.

23. Walsh S, Flanagan L, Quinn C, Evoy D, McDermott EW, Pierce A and Duffy MJ: mTOR in breast cancer: Differential expression in triple-negative and non-triple-negative tumors. Breast 21: 178-182, 2012.

24. Pantuck AJ, Seligson DB, Klatte T, Yu H, Leppert JT, Moore L, O'Toole T, Gibbons J, Belldegrun AS and Figlin RA: Prognostic relevance of the mTOR pathway in renal cell carcinoma: Implications for molecular patient selection for targeted therapy. Cancer 109: 2257-2267, 2007.

25. Chung JY, Hong SM, Choi BY, Cho H, Yu E and Hewitt SM: The expression of phospho-AKT, phospho-mTOR, and PTEN in extrahepatic cholangiocarcinoma. Clin Cancer Res 15: 660-667, 2009.

26. Yu G, Wang J, Chen Y, Wang X, Pan J, Li G, Jia Z, Li Q, Yao JC and Xie K: Overexpression of phosphorylated mammalian target of rapamycin predicts lymph node metastasis and prognosis of chinese patients with gastric cancer. Clin Cancer Res 15: 1821-1829, 2009.

27. Wang D, Chen J, Guo F, Chen H, Duan Z, Wei MY, Xu QM, Wang LH and Zhong MZ: Clinical significance of mTOR and p-mTOR protein expression in human colorectal carcinomas. Asian Pac J Cancer Prev 12: 2581-2584, 2011.

28. No JH, Jeon YT, Park IA, Kang D, Kim JW, Park NH, Kang SB and Song YS: Expression of mTOR protein and its clinical significance in endometrial cancer. Med Sci Monit 15: BR301-BR305, 2009.

29. Berven LA, Willard FS and Crouch MF: Role of the p70(S6K) pathway in regulating the actin cytoskeleton and cell migration. Exp Cell Res 296: 183-195, 2004.

30. Contessa JN, Hampton J, Lammering G, et al: Ionizing radiation activates Erb-B receptor dependent Akt and p70 S6 kinase signaling in carcinoma cells. Oncogene 21: 4032-4041, 2002.

31. Xiao L, Wang YC, Li WS and Du Y: The role of mTOR and phospho-p70S6K in pathogenesis and progression of gastric carcinomas: An immunohistochemical study on tissue microarray. J Exp Clin Cancer Res 28: 152, 2009.

32. Zhang Y, Ni HJ and Cheng DY: Prognostic value of phosphorylated mTOR/RPS6KB1 in non- small cell lung cancer. Asian Pac J Cancer Prev 14: 3725-3728, 2013.

33. Ji J and Zheng PS: Activation of mTOR signaling pathway contributes to survival of cervical cancer cells. Gynecol Oncol 117: 103-108, 2010.

34. Roulin D, Cerantola Y, Dormond-Meuwly A, Demartines N and Dormond O: Targeting mTORC2 inhibits colon cancer cell proliferation in vitro and tumor formation in vivo. Mol Cancer 9: $57,2010$. 